\title{
INTEGRACIÓN REGIONAL EN AMÉRICA CENTRAL, 1990-1997: LOS LÍMITES DEL GRADUALISMO ${ }^{1}$
}

\author{
José Antonio Sanahuja*
}

\section{INTRODUCCIÓN}

El dos de septiembre de 1997 los Presidentes centroamericanos emitieron la "Declaración de Nicaragua", en la que acordaron "iniciar el proceso de constitución, gradual y progresiva, de la Unión Centroamericana”, redactando un proyecto de Tratado Constitutivo. La decisión presidencial es un acontecimiento de gran trascendencia; con ella comienza una nueva etapa en el proceso de integración del istmo, y se intenta superar algunas de las carencias y limitaciones que se han ido presentando en la etapa anterior del mismo.

En esta misma reunión Presidencial se celebró el $\mathrm{X}$ Aniversario del Acuerdo de Paz firmado en agosto de 1987 en la "Cumbre" de Esquipulas II. No se trata de una mera coincidencia cronológica. Desde su inicio, el proceso de Esquipulas ha tenido una clara vocación centroamericanista. La crisis que sufría la región no era una simple agregación de problemas nacionales. La paz, la democracia y el desarrollo exigían soluciones de carácter regional. La reactivación del proceso de integración en la Reunión Presidencial de Antigua Guatemala de junio de 1990 ha sido la continuación lógica y necesaria. Conforme han ido materializándose los acuerdos de paz, la agenda de las Reuniones presidenciales se ha ido desplazando hacia temas económicos, sociales y ambientales. El renovado proceso de integración regional se ha convertido en una prioridad, en la medida que es un instrumento clave para el desarrollo y para la búsqueda de nuevas formas de inserción internacional en un mundo que, tras el final de la guerra fría, aparece dominado por las dinámicas de la mundialización económica.

A pesar de sus logros, el proceso de Esquipulas no puede darse por concluido. Paz, democracia y desarrollo -los tres objetivos, interdependientes e inseparables, del Acuerdo de Paz- no están plenamente asentados en la región. Aún hay tareas pendientes en materia de libertades democráticas, plena vigencia de los derechos humanos, desmilitarización o reforma del Estado. La recuperación económica tiene aún bases frágiles, y las sociedades centroamericanas siguen soportando niveles de pobreza infamantes. Las dinámicas de exclusión que dieron origen a la violencia política y los conflictos armados no han sido superadas, e incluso se han agravado por efecto de políticas de ajuste con un fuerte coste social. Por ello, el desarrollo económico y social y la lucha contra la pobreza y la exclusión, una vez logrado el cese el fuego, son condiciones necesarias para consolidar la democracia y asegurar una paz duradera. Es en este contexto en el que el proceso de integración y el proyecto de constitución de la Unión Centroamericana cobra pleno sentido: configurarse como un instrumento efectivo para la consolidación de la paz y la democracia y promover un desarrollo humano, justo y sostenible para el conjunto de la población centroamericana.

A la luz de esas metas, este artículo pretende examinar críticamente la evolución del proceso de integración regional en el periodo 1990-1997. Para ello se analiza tanto el marco jurídico e institucional creado en ese periodo como la profunda reforma institucional acordada en julio de ese último año. En apartados posteriores se aborda el nuevo diseño de la integración económica, sus logros y obstáculos, y los vínculos extrarregionales del mismo. Se omiten, por razones de espacio, las dimensiones social, ambiental y de seguridad del proceso integracionista, cada una de las cuales tendría la entidad suficiente como para ser objeto de un estudio específico. A partir de este análisis se intentarán identificar las carencias del diseño integracionista adoptado en el periodo 1990-1997 en el plano político y económico. Finalmente, de cara a la futura "Unión Centroamericana”, se abogará por una "integración auténtica” que supere las carencias del actual modelo integracionista y pueda llegar a ser en un apoyo efectivo al desarrollo económico, al progreso social y a una mejor inserción internacional del istmo.

Prof. del Dpto. de Relaciones Internacionales, Fac. de Ciencias Políticas y Sociología. Universidad Complutense de Madrid.

1. Este artículo se basa en la Ponencia presentada en el VI Encuentro de Latinoamericanistas Españoles, celebrado en Madrid entre el 29 de septiembre y el 1 de octubre de 1997. José Ángel Sotillo y Javier Fernández hicieron valiosas aportaciones, por las que el autor desea expresar su agradecimiento. De las opiniones y errores aqui vertidos sólo el autor es el responsable. 


\section{ESQUIPULAS I: EL RELANZAMIENTO DEL PROCESO DE INTEGRACIÓN Y EL NUEVO CONTEXTO INTERNACIONAL}

\subsection{Los años ochenta: el colapso del Mercado Común Cen- troamericano y el impulso político para la reactivación}

La expresión "década perdida" resume adecuadamente la realidad económica de la integración centroamericana en los años ochenta. El efecto combinado de la recesión económica mundial, la crisis de la deuda, el agotamiento de la sustitución de importaciones y los conflictos armados dieron lugar a la peor crisis de la historia reciente de Centroamérica. La crisis del modelo de integración y la caída del comercio intrarregional a mínimos históricos fue a la vez causa y consecuencia de estos factores. Desde el punto vista político, sin embargo, la realidad fue otra: la cumbre presidencial de Esquipulas I dio inicio a un proceso de concertación política del que la nueva integración centroamericana es un resultado inmediato.

Los países de la región enfrentaron la recesión con medidas unilaterales de corto plazo, imponiendo nuevos obstáculos a un comercio intrarregional que, desde la década de los setenta, había empezado a languidecer. Entre 1980 y 1986 disminuyó un 60\%, pasando de 1.135 a 413 millones de dólares. El casi total colapso del mercado regional también se debió a la volatilidad de los tipos de cambio y a la acumulación de deudas entre los distintos miembros del MCCA, que provocaron la quiebra del sistema regional de pagos. De esta forma el mercado regional, lejos de ser un factor amortiguador de la crisis, contribuyó a agravarla.

La década también estuvo dominada por las políticas de estabilización y ajuste adoptadas a instancias de la Agencia para el Desarrollo Internacional de Estados Unidos (USAID), el Fondo Monetario Internacional (FMI) y el Banco Mundial. Estas políticas promovieron una nueva estrategia de desarrollo liberal-exportadora, que ha ido dejando atrás el viejo modelo "de sustitución de importaciones" del MCCA. El mercado regional perdió atractivos ante las oportunidades comerciales abiertas por la Iniciativa para la Cuenca del Caribe (ICC) y los generosos incentivos a la exportación a terceros mercados adoptados por los gobiernos de la región. Las "maquilas" o industrias de ensamblaje y los productos "no tradicionales" se fueron convirtiendo en los sectores exportadores más dinámicos (Gallardo 1988, Tucker 1989).

Los organismos financieros internacionales se opusieron a la integración y contribuyeron directa o indirectamente a desarticular el MCCA, al que atribuyeron parte de la responsabilidad de la crisis económica. Algunos de los compromisos de liberalización acordados con estos organismos significaron la ruptura del nuevo Arancel Externo Común, adoptado en 1985 tras diez años de laboriosas negociaciones, y el abandono de la Unión Aduanera ${ }^{2}$. Es oportuno recordar que la actitud de Estados Unidos hacia el MCCA fue casi siempre hostil, debido a que su reactivación no era compatible con una estrategia regional que pretendía aislar por todos los medios al Gobierno Sandinista (Bulmer-Thomas 1992: 46, Sanahuja 1996: I, 235).
Desde el punto de vista de la concertación política, como indicamos, se registraron avances de gran trascendencia. La reunión de Esquipulas I (mayo de 1986) -la primera "cumbre" presidencial en 23 años- inició una dinámica de concertación política y cooperación económica y social que aún se mantiene, y que se materializado en 19 reuniones presidenciales que han facilitado la solución negociada a los conflictos de la región, han impulsado la democratización y han hecho posible la reactivación del MCCA. Cierto es que al finalizar el decenio el MCCA estaba desarticulado desde el punto de vista institucional y económico y el comercio intrarregional, aun con la recuperación registrada desde 1987, era muy inferior al alcanzado años antes. Pero sin el proceso de paz, sin el impulso político de las "Cumbres" presidenciales y sin la legitimidad que éste adquirió a través del incipiente proceso de democratización, difícilmente hubiera podido abordarse a partir de 1990 los problemas económicos y sociales de la región y la reactivación del proceso de integración.

\subsection{El relanzamiento del proceso y sus principales hitos, 1990-1997}

La integración regional volvió a ser un tema relevante en la agenda política y económica centroamericana debido a los cambios producidos en el escenario regional y mundial, en los que el año 1990 representa un evidente punto de inflexión: se reanudaron las negociaciones de paz en El Salvador, y tras el triunfo de una coalición opositora en las elecciones en Nicaragua, comenzó la desmovilización de la "contra" y se logró dar fin a la guerra. Todos los países de la región celebraron elecciones presidenciales entre 1989 y 1990, que llevaron al poder a opciones de derecha y situaron en los ministerios económicos a una nueva generación de tecnócratas decididos a aplicar el denominado "Consenso de Washington" de inspiración neoliberal (Williamson 1990: 5-38). Este hecho, unido a la ausencia de los sandinistas, permitirá la definición de un nuevo consenso en las instancias regionales.

No menos importantes han sido los cambios registrados en el escenario internacional de la posguerra fría. Ese escenario ha facilitado la resolución pacífica de los conflictos regionales, pero también redujo la importancia estratégica de Centroamérica, que se enfrentó al riesgo de quedar marginada de los flujos comerciales, financieros y tecnológicos del mundo de la globalización. Esta percepción se vio reforzada por acontecimientos como la Iniciativa de las Américas, propuesta en junio de 1990 por el Presidente Bush, la formación del Mercado Único Europeo de 1992, y las negociaciones de la "Ronda Uruguay" del GATT, que anunciaban un mundo en el que coexistirían grupos regionales y un régimen de apertura multilateral. En este escenario, la integración regional se convirtió en un imperativo estratégico (Lizano 1994: 11).

2. El nuevo AEC centroamericano fue adoptado en 1986. Costa Rica lo abandonó unilateralmente en 1987, en el marco de las negociaciones de su primer Programa de Ajuste Estructural (PAE-I) con el Banco Mundial, y en años posteriores otros países siguieron su camino. 
Centroamérica se ha enfrentado al nuevo escenario económico internacional a través de una estrategia que pretende combinar la integración regional, la liberalización comercial y la intensificación de los vínculos comerciales con el exterior. Dicha estrategia fue delineada en el Plan de Acción Económico para Centroamérica (PAECA), aprobado en la reunión presidencial de Antigua Guatemala de junio de 1990. El PAECA pretendió promover «(...)la reconstrucción y transformación de las estructuras productivas y tecnológicas de los países centroamericanos, como base para una reinserción eficiente y dinámica en el mercado mundial» (Declaración de Antigua, punto 30). Para ello planteó las siguientes metas:

a) Crear un nuevo un nuevo marco jurídico, institucional y operativo de la integración.

b) Establecer un calendario de desgravación arancelaria con el objeto de reactivar el comercio intrarregional y reestablecer el arancel externo común.

c) Poner en funcionamiento el Sistema Regional de Pagos y el "Programa de desmantelamiento de los obstáculos al comercio interregional".

d) Adoptar una política coordinada ante el GATT, la Unión Europea y Estados Unidos para obtener mejores condiciones de acceso a mercados externos.

e) Adoptar una política de reconversión industrial, con miras a la promoción de exportaciones, y coordinar la política agrícola.

A través del PAECA se optaba por un nuevo modelo de integración regional, compatible con las políticas de apertura y liberalización comercial derivadas de los programas de ajuste estructural que en ese periodo estaban aplicando todos los países de la región. El nuevo modelo tiene como objetivo el crecimiento basado en las exportaciones, y no la industrialización basada en un mercado interno ampliado con altos niveles de protección, como ocurrió en los años sesenta. Según este nuevo enfoque, un mercado regional ampliado con bajos niveles de protección externa aumentaría la eficiencia y la competitividad y alentaría la inversión extranjera. El mercado regional, en suma, se configura como plataforma para mejorar la inserción en la economía mundial -"un mercado común para exportar"- y reforzar la capacidad negociadora del istmo con otros países y bloques subregionales (Rodas 1994: 187).

El PAECA ha sido el primer paso de un proceso de paulatina renovación de la integración regional, que entre 1990 y 1996 se ha desarrollado a través de diversos programas sectoriales y de varios tratados y convenios -no ha habido en Centroamérica un "tratado marco" de la integración- que han ido definiendo una institucionalidad regional cada vez más amplia y compleja. Los más importantes son los siguientes.

a) El Protocolo de Tegucigalpa (1991), que crea el Sistema de la Integración Centroamericana (SICA) y establece un nuevo marco político e institucional.

b) El Protocolo de Guatemala (1993), que crea el "Subsistema de Integración Económica".

c) La "Alianza para el Desarrollo Sostenible" (ALIDES) (1994), que define una nueva estrategia de desarrollo de la región. d) El Tratado de Integración Social (1995), que crea el "subsistema de la integración social".

e) El Tratado de Seguridad Democrática (1995), que define un nuevo régimen de seguridad regional basado en la primacía del Estado de derecho y la confianza mutua.

\section{EL NUEVO MARCO JURÍDICO E INSTITUCIO- NAL: EL SISTEMA DE LA INTEGRACIÓN CEN- TROAMERICANA (SICA)}

\subsection{Cooperación vs. integración: las debilidades del siste- ma institucional y normativo}

Al finalizar la década de los ochenta el MCCA se encontraba con una situación jurídica anómala y un entramado institucional heterogéneo y desarticulado, en el que coexistían -sin vínculos formales entre sí- instituciones técnicas como el BCIE o la SIECA, e instancias de naturaleza política como la Reunión de Presidentes o el Parlacen (Chamorro y Nájera 1996: 67).

La renovación del sistema institucional y normativo de la integración fue abordada en la XI Cumbre de Presidentes, celebrada en Tegucigalpa el 13 de diciembre de 1991. En dicha reunión se aprobó el Protocolo a la Carta de la Organización de Estados Centroamericanos (ODECA $)^{3}$, conocido como Protocolo de Tegucigalpa. El Protocolo, que incluye entre sus Estados parte a Panamá y está abierto a la adhesión de Belice, aspira a hacer de Centroamérica «(...)una región de paz, libertad, democracia $y$ desarrollo». Para ello reafirma los propósitos integracionistas de los Estados firmantes y establece el Sistema de la Integración Centroamericana (SICA) como «nuevo marco institucional de la integración centroamericana», sustituyendo a la ODECA. El SICA cuenta con personalidad jurídica, y sede en San Salvador. El SICA empezó a funcionar el 1 de enero de 1993, y desde el 26 de marzo de 1996 lo integran los seis países de la región.

Los objetivos del SICA son muy diversos, heterogéneos y ambiciosos, e incluyen la consolidación de la democracia y el Estado de derecho, la adopción de un nuevo modelo de seguridad regional, el crecimiento económico, el bienestar social y la superación de la pobreza, la unión económica y la mejora de la inserción de la región en la economía mundial. Para la realización de estos objetivos, el SICA establece una nueva estructura institucional de la integración, que integra las viejas organizaciones regionales

3. La Carta de la Organización de Estados Centroamericanos (ODECA), conocida como "Carta de San Salvador", fue adoptada en 1951, y se reformó en 1962. La ODECA se configuraba como un marco de concertación y cooperación política ente los cinco estados firmantes, considerados según la Carta "una comunidad económica y política que aspira a la integración de Centroamérica”. En la práctica, la ODECA nunca llegó a funcionar, y su reforma, dando lugar al Sistema de la Integración Centroamericana (SICA), fue más un recurso jurídico que una cuestión de fondo. Las ambigüedades que persistieron en relación a la continuidad de la ODECA motivaron, sin embargo, dos resoluciones de la Cumbre de Presidentes que aclaraban que la creación del SICA significaba la extinción de la ODECA (Guerra-Borges 1993: 59). 
y los nuevas instancias de carácter político -incluyendo el Parlacen- con una "lógica sistémica", y precisa el papel director que corresponde a la Reunión de Presidentes (ver cuadro 1). Esta estructura institucional se ha visto desarrollada posteriormente con el "Subsistema de la Integración Económica", el "Subsistema de la Integración Social", y la creación de órganos específicos en el ámbito ambiental y de seguridad, definiendo un panorama institucional muy complejo y diverso.

La aprobación del Protocolo de Tegucigalpa y el establecimiento del SICA han sido acontecimientos de gran relevancia. En primer lugar, han asentado la dimensión política que ahora tiene el proceso, superando el carácter estrictamente económico que la integración tuvo en los años sesenta y setenta. En segundo lugar, al pretender constituir «(...) una región de paz, libertad, democracia y desarrollo», el SICA ha establecido un vínculo expreso entre la paz, la democracia, el Estado de derecho, el desarrollo económico y social y la integración regional. El SICA se convierte, de esta forma, en un instrumento para dar continuidad a las metas establecidas en Esquipulas II y, quizás lo más significativo, el proceso de integración puede convertirse en un factor de consolidación democrática para los regímenes que en él participan.

El diseño institucional del SICA, en tercer lugar, ha contribuido a unificar -aunque no a ordenar- el entramado de organizaciones e instancias regionales hasta entonces en funcionamiento. Al institucionalizar la Reunión de Presidentes como órgano supremo del mismo, ha confirmado su papel en la dirección política de la integración. Las decisiones de los órganos del SICA son en principio obligatorias -se genera así un "derecho derivado" de la integración- aunque deberán ser adoptadas por consenso. El SICA incluye, además, órganos e instituciones permanentes de vocación centroamericanista, como son la Secretaría General, el Parlacen y la Corte Centroamericana de Justicia.

El establecimiento de la Corte Centroamericana de Justicia (CCJ) como órgano jurisdiccional del SICA es un acontecimiento de indudable trascendencia en el nuevo diseño institucional de la integración. Como tribunal internacional regional, la jurisdicción de la CCJ es obligatoria y se extiende a todos los asuntos que le sometan los Estados parte, así como a las controversias surgidas entre personas físicas y jurídicas, Estados parte y órganos del SICA ${ }^{4}$. La CCJ también tiene competencias consultivas en relación, entre otras materias, a la interpretación y aplicación del derecho de la integración centroamericana.

La jurisprudencia de la CCJ puede convertirse en uno de los más importantes fundamentos del proceso de integración, promoviendo la seguridad jurídica y haciendo de Centroamérica una comunidad de derecho. En su corta andadura -la CCJ comenzó a funcionar en octubre de 1994 en su sede de Managua- este Tribunal ya ha emitido diversas resoluciones interpretando el derecho de la integración centroamericana. (Corte Centroamericana 1995 y 1996).

Las limitaciones del SICA, sin embargo, también son muy visibles. El Protocolo describe con cierto detalle su estructura institucional, pero es ambiguo y generalista en lo referido a su naturaleza y objetivos. Estos últimos, muy ambiciosos, contrastan con la parquedad de medios institucionales y jurídicos puestos a su disposición. Es importante resaltar que la creación del SICA no comporta una transferencia de competencias nacionales a órganos de la integración. En realidad el SICA es un marco institucionalizado y permanente de cooperación intergubernamental más que una verdadera organización de integración de naturaleza supranacional. Según el artículo 22 del Protocolo de Tegucigalpa, las decisiones del Consejo de Ministros serán obligatorias para los Estados miembros en tanto no se opongan a la legislación interna de éstos. La Corte Centroamericana de Justicia, en respuesta a una pregunta del Secretario General del SICA, señaló en su Resolución n ${ }^{\circ} 5$ del 20 de octubre de 1995 en relación a las decisiones del Consejo de Ministros que «(...)la obligatoriedad de estas disposiciones cede ante la presencia de la ley interna». La única excepción es la propia Corte. En su Estatuto se afirma claramente su naturaleza supranacional y el carácter obligatorio de su jurisdicción. Por todo ello tampoco puede hablarse de un verdadero equilibrio de poderes entre los órganos e instituciones del Sistema, como la Corte de Justicia o el Parlacen.

La ausencia de órganos con la capacidad de generar un ordenamiento jurídico de rango superior al de los Estados miembros, la "regla del consenso" y la obligatoriedad de las decisiones sólo para aquellos Estados que las suscriban - a manera de "cláusula opcional" - suponen que el SICA no cuenta con los medios jurídicos e institucionales necesarios para el logro de sus objetivos sobreponiéndose a intereses nacionales concretos. En estas limitaciones radican, como veremos, las dificultades que el SICA ha experimentado para lograr algunos de sus objetivos más inmediatos para la formación de un verdadero mercado común.

El importante papel que el Protocolo de Tegucigalpa ha otorgado a la Reunión de Presidentes como órgano de deliberación y toma de decisiones es el resultado de un momento histórico en el que éstas se han caracterizado por un fuerte dinamismo y un alto grado de homogeneidad ideológica y consenso político. Estas circunstancias, sin embargo, pueden ser algo pasajero. Cabe preguntarse, en consecuencia, si el proceso de integración podrá continuar con el mismo ímpetu si se agota el actual "dinamismo presidencial" (CEPAL 1997a).

Por otra parte, no existen mecanismos efectivos para asegurar el cumplimiento efectivo de las numerosas decisiones adoptadas en las Reuniones Presidenciales y en los distintos Consejos de Ministros -más de 2000, según un inventario de CEPAL (1997b: 5). El cumplimiento de estas decisiones, de naturaleza esencialmente política, se ha visto a menudo relegado ante los imperativos de la coyuntura política y de las prioridades gubernamentales y legislativas nacionales, que no suelen guardar relación con lo que se

4. Se exceptúan las controversias fronterizas, territoriales y marítimas, para cuyo conocimiento se requiere la solicitud de todas las partes concernidas, y los asuntos relacionados con los derechos humanos, que competen a la Corte Interamericana de Derechos Humanos (artículos 22 y 25 del Estatuto de la CCJ). 
debate y decide a nivel regional. Este vacío no puede ser colmado por los órganos regionales, que como hemos señalado no tienen ni las competencias ni las capacidades necesarias para ello.

El Protocolo de Tegucigalpa, finalmente, no representa un nuevo "Tratado Marco" de la integración, ya que dejaba al margen la dimensión económica del proceso, contemplada por el Tratado General de 1960. Este y otros temas han sido objeto en años posteriores de nuevos tratados y convenios: el Protocolo de Guatemala sobre integración económica, el Tratado de Integración Social y el Tratado Marco de Seguridad Democrática Centroamericana ${ }^{5}$. Cada uno de ellos ha agregado al SICA un nuevo "subsistema" -de la integración económica, de la integración social...- con nuevas instituciones, objetivos, funciones y mecanismos de toma de decisiones, no siempre coincidentes. Ninguno de los nuevos Tratados modifica la naturaleza esencialmente intergubernamental del SICA. Estos nuevos acuerdos, en consecuencia, lo han hecho mucho más diverso y complejo, pero no más eficaz. En la práctica, el SICA ha unificado las diferentes instituciones e instancias de la integración, pero no ha logrado ordenarlas -tal y como pretendía- con una lógica "sistémica" funcional o sectorial, ni les ha otorgado la autonomía y las competencias necesarias para poder llevar cabo los ambiciosos objetivos del Sistema. A mediados de 1997 existían, según un inventario realizado por CEPAL, 55 instancias políticas y administrativas: 21 órganos regionales, 10 secretarías sectoriales, 16 "instituciones", 2 órganos de consulta, y otras 5 instancias de difícil clasificación (CEPAL 1997). Para agravar el problema, sus funciones y competencias no siempre han sido definidas claramente, y la "autonomía funcional" que el Protocolo de Tegucigalpa reconoce a algunas de ellas no ha sido delimitada. Por otra parte, no todos los países del istmo han ratificado todos los Tratados. Aunque en algunos casos ello se debe a los lógicos retrasos de los procedimientos parlamentarios nacionales, en otros casos refleja la resistencia de algunos países a incorporarse a una parte del proceso. En la práctica, ello ha definido una integración "de geometría variable" (ver cuadro 2 ).

La falta de eficacia del entramado institucional del SICA, sin embargo, no se debe sólo a las carencias del ordenamiento jurídico que le ha dado origen y a su visible fragmentación institucional. La notoria falta de personal y las limitaciones presupuestarias del Sistema impiden que éste cumpla eficazmente su cometido. El retraso en el pago de las cuotas de los Estados miembros y la parquedad de las contribuciones realizadas suponen que una buena parte de las actividades de estas entidades descansan, de hecho, en recursos de la cooperación externa. Los Presidentes acordaron establecer un sistema de financiación automática de las instituciones regionales en la XVII Reunión Presidencial (San Pedro Sula, diciembre de 1995), pero esta decisión -como otras muchas- no ha llegado a materializarse ${ }^{6}$.

\subsection{El papel del Parlamento Centroamericano y el "déficit democrático" de la integración}

Con la creación del Parlacen la región se ha dado un alto foro de deliberación política de vocación centroamericanista, con la legitimidad democrática que se deriva de su elección por sufragio universal directo, y se ha fortalecido la dimensión política de la integración (Abraham 1989, Fernández et alii 1990 e IRELA 1990).

El 28 de octubre de 1991 el Parlacen se constituyó oficialmente en Guatemala. El día 22 de octubre de 1996 el Parlacen inició su segundo periodo de sesiones (19962001), con la participación de representantes de El Salvador, Guatemala, Honduras, Nicaragua y Panamá. En la actualidad Costa Rica es el único país que no ha ratificado el Tratado Constitutivo ni los Protocolos posteriores.

La actuación del Parlacen en el proceso integracionista ha estado determinada por las limitadas competencias con las que fue creado. Según su Tratado Constitutivo es un órgano regional "de planteamiento, análisis y recomendación”, que sirve como foro de deliberación, puede impulsar iniciativas y proyectos de tratados centroamericanos y conoce los informes de las organizaciones regionales. El Protocolo de Tegucigalpa, que establece el SICA, no ha atribuido competencia alguna al Parlacen en materia de control o de toma de decisiones, ni instituye un proceso regularizado de consulta o de codecisión por el que éste pueda emitir opiniones o dictámenes, o introducir enmiendas en las decisiones de los órganos del SICA, tal y como ocurre en el Parlamento Europeo. Los tratados posteriores tampoco otorgan al Parlacen papel alguno en el proceso decisorio ni en la creación del derecho derivado de la integración. El propio Parlacen considera que como Cámara regional debe tener el poder de iniciativa legislativa en materia de integración para superar el "déficit democrático" que caracteriza al sistema institucional del SICA (ver Iniciativa 121/35 del 31-V-94).

Las limitadas competencias y atribuciones del Parlacen y su débil articulación con los órganos e instituciones de la integración no han impedido que esta Cámara haya impulsado hasta 221 iniciativas para profundizar el proceso de integración y promover el Estado de derecho y los derechos humanos (Parlamento Centroamericano 1996). Entre estas iniciativas destacan el proyecto de "Carta de la Comunidad de Estados Centroamericanos" (Iniciativa 07/03 del 25-XI-91), las propuestas sobre Ciudadanía Centroamericana (Iniciativas 60/123 de 20-IV-93 y 64/25 de 28-VI-93), diversas iniciativas sobre armonización de legislaciones en campos como el medio ambiente, los derechos de los trabajadores -incluyendo un proyecto de Código Laboral Centroamericano-, legislación penal,

5. En ejercicio de sus competencias consultivas y en respuesta a una pregunta formulada por el Secretario General del SICA, la Corte Centroamericana de Justicia emitió el 24 de mayo de 1995 la Resolución $\mathrm{n}^{\circ} 3$, en la que se afirma que el Protocolo de Tegucigalpa «...es el Tratado constitutivo marco de la integración centroamericana, y por tanto el de mayor jerarquia y la base fundamental de cualquier otra normativa centroamericana».

6. Las contribuciones nacionales representan unos 3 millones de dólares al año por cada Estado miembro, que suponen entre el $0,2 \%$ y el $0,3 \%$ de su gasto gubernamental combinado. El Parlacen supone el $47 \%$ de las contribuciones. SIECA el 15\%, la Corte de Justicia el 11\% y la Secretaría General el 5,5\%. Según un diagnóstico de CEPAL-BID, el correcto funcionamiento de las Instituciones exigiría duplicar las aportaciones y redistribuirlo de forma que los órganos "técnicos" tengan mayor participación. Ver Inforpress Centroamericana 16-23 de junio y 23-30 junio de 1997. 
lucha contra el narcotráfico, libre circulación y eliminación de barreras a los intercambios regionales.

Hay que señalar, sin embargo, que el Parlacen se ha visto cuestionado por importantes sectores de la opinión pública. El Parlacen no es ajeno a los problemas de legitimidad que afectan a las instituciones parlamentarias de la región, con los agravantes que suponen sus escasas competencias y el hecho de consumir el $47 \%$ del presupuesto de las instituciones regionales. Esta Cámara, por otra parte, incorpora como miembros ex-officio a los ex-presidentes y ex-vicepresidentes. El régimen de inmunidades garantizado por su Convenio Constitutivo ha sido utilizado de forma abusiva por parte de algunos de ellos para eludir la acción de la justicia ante casos de corrupción, lo que también ha contribuído a debilitar la imagen pública de esta Cámara.

\subsection{La participación de la sociedad civil en el proceso de integración regional}

La importancia de la participación activa de la sociedad civil ha sido puesta de relieve en las Reuniones Presidenciales. Sin menoscabo del legítimo papel que corresponde al Parlacen como instancia representativa y a los partidos políticos organizados a escala regional, la apertura de canales de diálogo con estas organizaciones permitiría introducir en su agenda las aspiraciones e intereses de los distintos sectores organizados a nivel regional. Dicha participación sin embargo, ha sido tardía y se ha visto obstaculizada por un ordenamiento institucional difuso y poco efectivo. Aunque existen plataformas regionales de amplia base, su influencia sobre el proceso de integración ha sido limitada debido a la escasa tradición de concertación de los sistemas políticos centroamericanos (Morales y Cranshaw 1997: V-VII).

El Comité Consultivo del SICA, previsto en el Protocolo de Tegucigalpa, entró en funcionamiento en noviembre de 1995. Está integrado por entidades representativas del sector empresarial, el campesinado, los trabajadores, las cooperativas, las universidades, las organizaciones indígenas y los municipios. Hay que anotar, sin embargo, que ni en el SICA ni en los diferentes subsistemas es preceptiva la consulta a estas instancias, y tampoco existe un procedimiento regularizado de participación de las mismas en el proceso de toma de decisiones.

La creación de plataformas regionales de las organizaciones de la sociedad civil es anterior al establecimiento de canales institucionalizados en el seno del SICA. Entre ellas destacan la Federación de Entidades Privadas de Centroamérica y Panamá (FEDEPRICAP) y la Iniciativa Civil para la Integración Centroamericana (ICIC) (Ossa 1996: 65-71). El carácter regional de estas plataformas revela que la sociedad civil está adaptando sus estrategias y enfoque a la integración regional, en mayor medida incluso que los partidos políticos. Estos procesos de organización revelan que se empieza a gestar una "integración desde abajo" que desborda el ámbito gubernamental. Sin contar con esta realidad y sin establecer cauces de diálogo y consulta permanente es difícil suponer que el proceso de integración sea duradero, y que llegue a ser un proyecto arraigado en las sociedades centroamericanas.

\subsection{La reforma del SICA: ¿racionalización institucional o reorientación del proceso?}

En la XIX Reunión Presidencial (Panamá, 12 de julio de 1997) se decidió emprender una profunda reforma del SICA con objeto de superar los problemas de descoordinación, ineficacia y dispersión institucional acumulados desde 1990. Partiendo de un informe elaborado por CEPAL con fondos del BID, los Presidentes aprobaron el documento Lineamientos para el fortalecimiento y racionalización de la institucionalidad regional. En este documento se reafirma el papel director de la Reunión de Presidentes y el Consejo de Ministros y se proponen cambios significativos para el resto de las instancias e instituciones del Sistema. Estas decisiones tendrán que materializarse entre 1997 y 1998 y se concretaría, según los Presidentes, en un nuevo instrumento jurídico único:

- En relación al Parlamento Centroamericano se acordó elaborar un Protocolo modificatorio de su Tratado Constitutivo, modificando las disposiciones referidas a los privilegios e inmunidades de los parlamentarios; otorgando a los Presidentes la facultad de aprobar su presupuesto, que se irá reduciendo paulatinamente, establecer un calendario y un sistema electoral coincidente con el de los Estados miembros, y coordinar su agenda con la de los Parlamentos nacionales.

- En relación a la Corte Centroamericana de Justicia se acordó revisar las inmunidades y privilegios de sus magistrados; reducir su número a uno por país; fortalecer su papel en materia de arbitraje comercial;derogar el artículo 22 (f) de su Estatuto -este artículo, rechazado por Costa Rica, daba competencia a la Corte en controversias entre distintos poderes dentro de un Estado miembro- y, con objeto de reducir gastos, establecer un sistema de funcionamiento a base de dietas.

- Se unificarán las secretarías en una sola Secretaría General con sede en San Salvador. Esta Secretaría unificada asumirá las funciones de las Secretarías de todos los Consejos, Comisiones, Comités y Foros Sectoriales que cuenten con algún tipo de servicio de Secretariado. La Secretaría General Unificada estará conformada por la Secretaría General y tres direcciones de área: económica, social y ambiental. La creación de la Secretaría General unificada, y la readecuación de los órganos e instituciones centroamericanas se hará en un instrumento jurídico único, a modo de "Tratado de Fusión".

- Se elaborará un presupuesto único por parte de la Secretaría General, el cual será aprobado por el Consejo de Ministros de Relaciones Exteriores en consulta con el Consejo de Ministros de Integración Económica.

- Se decide crear un Comité Consultivo único y elaborar un reglamento para la participación de la sociedad civil en el proceso. 
Las medidas parecen acertadas desde el punto de vista de la racionalización administrativa, y parecen augurar un entorno institucional más favorable para la coordinación y el seguimiento de las decisiones adoptadas. No se modifica, empero, la atribución de competencias a los órganos administrativos, con lo que la nueva Secretaría General Unificada no se ve fortalecida desde el punto de vista normativo. Los cambios operados en el Parlacen y la Corte de Justicia no modifican en lo esencial el papel periférico -particularmente en el caso del Parlacen- que tienen estos órganos dentro del Sistema y pueden debilitar su carácter de "órganos permanentes" del Sistema, con lo que el carácter Presidencialista del mismo se ha visto reforzado. Ambos órganos han expresado su oposición a las reformas. La Corte de Justicia señala que el nuevo sistema de sesiones ad hoc deteriora la seguridad jurídica de la integración. El Parlacen, por su parte, ha reclamado que las reformas den carácter "comunitario" al SICA con objeto de que esta Cámara obtenga verdaderos poderes de consulta y control, al estilo de los que posee el Parlamento Europeo ${ }^{7}$.

En septiembre de 1997, en una Reunión Extraordinaria celebrada en Managua, los Presidentes se reunieron para debatir el nuevo instrumento jurídico marco de la integración y la reorientación del proceso que las decisiones del mes de julio estaban anunciando. Basándose en una propuesta de El Salvador basada en la experiencia de la Unión Europea, los Presidentes acordaron «(...) iniciar el proceso de constitución, gradual y progresivo, de la Unión Centroamericana, como expresión superior de la asociación comunitaria estipulada en el Protocolo de Tegucigalpa de 1991». A tal efecto se anunció la constitución de un "grupo de alto nivel" que elaboraría el proyecto de Tratado de la Unión, que establecerá sus etapas y plazos ${ }^{8}$.

Aunque la Declaración de Nicaragua es ambigua respecto al alcance de la Unión -entre otras cosas, para superar las reticencias de Costa Rica- no cabe duda de que el proyecto de la Unión Centroamericana, como ya señalamos, abre una nueva etapa en el proceso de integración, y representa una oportunidad histórica para dotarle de naturaleza supranacional, hacer de Centroamérica una verdadera comunidad de derecho, y reforzar su legitimidad democrática.

\section{LIBERALIZACIÓN COMERCIAL Y "REGIONA- LISMO ABIERTO": LOS DILEMAS DE LA INTE- GRACIÓN ECONÓMICA}

El relanzamiento del proceso de integración se ha traducido en un amplio proceso de liberalización comercial y convergencia arancelaria que ha permitido la recuperación del comercio intrarregional, que en 1994 logró superar el máximo histórico de 1980. Se ha optado por un modelo de integración gradual y flexible que permite que algunos países progresen más rápido, y dos de ellos -Guatemala y El Salvador- acordaron en julio de 1996 establecer una Unión Aduanera. Finalmente, a través del "Protocolo de Guatemala” y de otros instrumentos se ha restablecido el marco institucional y normativo de la integración.
Estos importantes avances no deben ocultar que la integración económica está en una fase aún incipiente y hay muchos interrogantes respecto a su viabilidad y futuro. El incumplimiento de compromisos, el retraso en la ratificación de los convenios, la asimetría de las relaciones comerciales, las tendencias centrífugas, las debilidad de las políticas de apoyo, la precariedad institucional, la falta de participación social y los límites que ha encontrado el proceso de liberalización son algunos de los problemas que, al igual que en el ámbito de la integración política, van a requerir respuestas audaces para dar continuidad al proceso y asegurar que éste responde a las aspiraciones de progreso económico y social de los pueblos de la región.

\subsection{Liberalización comercial, convergencia arancelaria y recuperación de los intercambios}

El punto de partida de la reactivación del MCCA es el Programa de Acción Inmediata (PAI) elaborado en 1988 por los Presidentes Centroamericanos para coordinar la cooperación externa solicitada en apoyo del proceso de paz de Esquipulas. Este Plan contó con un decidido apoyo de Naciones Unidas y la Comunidad Europea, e incluía la reactivación del Sistema Regional de Pagos y un programa de desmantelamiento de obstáculos al comercio intrarregional.

El Sistema Regional de Pagos tuvo una vida efímera. Comenzó a operar en diciembre de 1990, cesó sus operaciones en noviembre de 1991 y fue definitivamente abolido en marzo de 1992 (Guerra-Borges s.f. y de Juan 1996). La liberalización de los intercambios, sin embargo, ha progresado de forma continuada. En la X Reunión Presidencial (San Salvador, julio de 1991) se suscribió el "Acuerdo Multilateral Transitorio de Libre Comercio", que permitió la reincorporación de Honduras al MCCA. También se aprobó el "Plan de Acción Agrícola", incluyendo por primera vez en la historia del MCCA al sector agropecuario.

En San Salvador también se decidió restablecer el arancel externo común (AEC) y, por tanto, avanzar hacia la unión aduanera. El proceso de negociación culminó en junio de 1992. El nuevo Arancel Uniforme Centroamericano de Importación oscilaría entre un mínimo del $5 \%$ y un máximo del $20 \%$, con ciertas excepciones para "bienes esenciales" y productos "sensibles", y un periodo transitorio especial para Nicaragua. Ello representó una sensible reducción de la protección efectiva y la dispersión arancelaria. A mediados de 1996, después de diversos retrasos e incumplimientos, el $95 \%$ de los rubros del AEC estaban ya equiparados, un $3 \%$, incluyendo el café, el azúcar, los derivados del petróleo y la carne de pollo, contaba con tarifas negociadas multilateralmente, y el tratamiento nacional se limitaba al $2 \%$, aunque en este grupo se incluyen

7. Inforpresss Centroamericana, 21-28 de julio de 1997

8. Los Presidentes debatieron la posibilidad de impulsar una "Federación"-una entidad de la que ya existía el precedente histórico, inmediatamente después de la independencia, de la Federación Centroamericana-, pero se optó por la idea de Unión tras considerar que ésta permitía combinar, según ámbitos, competencias "comunitarias", cooperación intergubernamental, y la preservación de la soberanía nacional. Ver Inforpress Centroamericana $\mathrm{n}^{\circ}$ 21, 8-15 de septiembre de 1997. 
excepciones significativas por razones fiscales. En diciembre de 1995 se acordó que los niveles arancelarios -actualmente entre $1 \%$ y $20 \%$ - disminuirían hasta situarse en 1999, según las posibilidades internas, en el rango 0-15\% (Alonso y Zamora 1996: 119-121). A mediados de 1996 también se habían adoptado los reglamentos relativos a Normas de Origen, Prácticas Desleales y Cláusulas de Salvaguardia, estando pendientes los que regularán la solución de controversias y los relativos a normas técnicas, sanitarias y fitosanitarias, ámbitos en los que aún existen restricciones al comercio intrarregional (CEPAL 1997b: 9-13).

Desde mediados de 1992 algunos países han acordado imprimir un ritmo más rápido al proceso, iniciando de hecho una integración "de dos velocidades" o "de geometría variable" (IRELA 1994: 35). En abril de 1992 Honduras y Guatemala firmaron un Acuerdo de Libre Comercio, Inversión e Integración Económica. En mayo se sumó a este Acuerdo la República de El Salvador. En la "Declaración de Nueva Ocotepeque" de mayo de ese mismo año esta agrupación, conocida como el "Triángulo del Norte", decidió establecer una zona de libre comercio, crear una unión aduanera a partir del 1 de abril de 1994, y liberalizar posteriormente el movimiento de personas y capitales. En abril de 1993 Nicaragua se sumó al Acuerdo, creándose el Grupo Centroamérica Cuatro (CA-4).

La recuperación del comercio intrarregional ha sido el resultado más visible de este proceso. La estabilidad macroeconómica y cambiaria también ha favorecido estos resultados. Entre 1990 y 1994 las exportaciones intrarregionales crecieron un $16 \%$ anual como promedio, permitiendo recuperar el volumen de intercambios anterior a la crisis. En 1995 las exportaciones intrarregionales alcanzaron los 1.489 millones de dólares. En 1994 y 1995 tales exportaciones representaron entre el $21 \%$ y el $22 \%$ del total. Esta proporción fue hasta 1994 la más elevada de todos los esquemas de integración subregional, incluyendo Mercosur. El mercado regional se situó entre el segundo y el tercer lugar en importancia para las exportaciones de la región.

A partir de 1994, sin embargo, el proceso se ha hecho más lento y las exportaciones intrarregionales están creciendo con menor dinamismo, por lo que la importancia relativa del mercado regional permanece estable. En 1995 y 1996 el MCCA fue el destino de entre el $22 \%$ y el $23 \%$ de las exportaciones totales de la región. El crecimiento de las exportaciones al mercado regional parece haberse detenido cuando apenas habían recuperado el nivel anterior a la crisis. Si atendemos a las importaciones el panorama es aún más preocupante: en 1980 el mercado regional era el origen del $18 \%$ de las importaciones. En 1984 descendieron al 9,4\%, y entre 1995 y 1996 se han situado en un magro 13,3\% del total (CEPAL 1995: 78, CEPAL 1997b: 7-9, 38-39). En ello han incidido variables de corto plazo -las dificultades económicas que Latinoamérica experimentó durante 1995 al propagarse los efectos de la crisis mexicana- pero también responden a los límites estructurales del modelo adoptado: el escaso alcance de una estrategia de integración que descansa, básicamente, en una liberalización comercial y la debilidad de un marco institucional y normativo que impide sobreponerse a los intereses nacionales que están detrás de las barreras no arancelarias, los recargos y sobretasas vigentes por razones fiscales, las barreras aduaneras y fiscales -entre ellas, las diferentes tasas de los impuestos de ventas y de los impuestos selectivos al consumo (alcohol, tabaco y bienes de lujo), que generan distorsiones comerciales y alientan el contrabando (Alonso y Zamora 1996: 122) - y otras medidas unilaterales que aún obstaculizan el libre comercio intrazonal y que indican que la plena vigencia del AEC y la Unión Aduanera son objetivos aún lejanos. El AEC se ha aplicado de forma tardía y parcial ${ }^{9}$, no todas las partidas están amparadas por los niveles acordados, y siguen registrándose retrasos. En junio de 1997, por ejemplo, se decidió posponer la equiparación del AEC, prevista para 1999, hasta el año 2005.

Dados los avances logrados en materia de libre comercio de bienes y la estructura del comercio exterior centroamericano -con predominio de los bienes industriales en el comercio intrarregional y de los bienes primarios y los "no tradicionales" en el extrarregional-, en el futuro inmediato la expansión de los intercambios dependerá de la eliminación de las barreras no arancelarias, de la plena liberalización del sector agropecuario y de los servicios, así como de esquemas más avanzados desde el punto de vista institucional y normativo; es decir, de lograr un verdadero mercado único que permita la libre circulación efectiva.

Puede alegarse que el comercio intrarregional no es tan importante como en el pasado, porque el nuevo objetivo de la integración es aumentar las exportaciones a terceros. Pero si aceptamos que la mejora de la competitividad es una condición necesaria para ello, las barreras que aún existen a la libre circulación de factores -en especial no arancelarias y las que dificultan o impiden la libre prestación de servicios y el comercio agropecuario- y la ausencia de políticas de apoyo son un motivo aún mayor de preocupación. La eliminación de estos obstáculos permitiría aprovechar economías de escala, reducir los costes de producción y aumentar la competitividad y la eficiencia productiva, tanto de los bienes que circulan dentro de la región como de los que se exportan a terceros mercados. Para ello, como han argumentado diferentes autores, el mínimo necesario a corto plazo es la consolidación de la unión aduanera (Bulmer-Thomas 1997, Caldentey 1997b).

Los servicios han estado hasta ahora prácticamente al margen de la liberalización. En el CA-4, el grupo que ha adoptado compromisos en este ámbito, los avances son muy limitados. La liberalización de los servicios es una cuestión esencial para profundizar el proceso de integración y en concreto para que éste contribuya a reducir los costes de producción -en los que los servicios de banca, seguros, finanzas, energía eléctrica o transporte tienen una

9. El Protocolo de Modificación al Código Aduanero Uniforme Centroamericano (CAUCA II) fue suscrito el 7 de enero de 1993, su entrada en vigor -el 1 de julio de 1996- se ha retrasado tres años, y sólo está vigente para Costa Rica, El Salvador y Nicaragua. Guatemala y Honduras aún no lo han ratificado. El CAUCA II, por otra parte, omite disposiciones clave para promover el proceso de integración, como la Cláusula Centroamericana de Excepción (Ossa 1994: 104-108). 
repercusión importante- e incrementar la eficiencia y la competitividad de la producción y de las exportaciones y de actividades que, como el turismo, son una importante fuente de empleo y divisas de la región (Bulmer-Thomas 1991: 7, 1992: 51, y Lizano 1994: 21).

En materia agropecuaria la desregulación y la liberalización de los intercambios ha sido significativa, pero el peso de las barreras no arancelarias -normas técnicas y fitosanitarias- es aún muy grande. Las dificultades existentes en este ámbito son particularmente importantes si consideramos la importancia del sector, que genera una cuarta parte del PIB, ocupa a la mitad de la población activa, es el origen del $50 \%$ de las divisas captadas por la región y es la base de su seguridad alimentaria. El sector agropecuario estuvo prácticamente al margen del MCCA en los años sesenta, pero en la actualidad se considera que la inserción internacional y el desarrollo mismo de la región dependen de la creación de un sector agroindustrial exportador eficiente y competitivo, y ello no será posible sin un verdadero mercado común agropecuario (Arias y Jované 1992: 83 145, Ramírez y Aguilar 1992: 173).

En el ámbito agropecuario, al igual que en otros, es patente la ausencia o la debilidad de las políticas regionales de apoyo establecidos para facilitar la reconversión y la adaptación de los sectores y empresas afectados por la liberalización -especialmente los pequeños y medianos campesinos basados en la producción de alimentos para el mercado interno- e inducir mejoras en la competitividad internacional. La necesidad de políticas de esta naturaleza para sectores como el agropecuario, el industrial o el turístico, para los pequeños y medianos productores y para promover la infraestructura y el desarrollo tecnológico, ha sido recogida explícitamente en diversas declaraciones presidenciales. Sin embargo, la falta de voluntad política para traducir los compromisos regionales en políticas nacionales, la debilidad de las instituciones regionales y la austeridad presupuestaria que afecta a los Gobiernos han impedido que en este ámbito las realizaciones hayan estado a la altura de los compromisos. En la práctica, las políticas regionales de apoyo dependen en gran medida de la cooperación externa, particularmente del BID, de la Comunidad Europea y de sus Estados miembros. Mención expresa merece el Sistema de Interconexión Eléctrica para los Países de América Central (SIEPAC), que permitirá articular un mercado regional de la energía mucho más eficiente ${ }^{10}$.

La libre circulación de trabajadores tampoco ha progresado por la extrema sensibilidad social y política de esta cuestión. Se ha indicado, sin embargo, que es posible realizar avances modestos en esta materia, liberalizando la prestación de ciertos servicios profesionales, regulando la migración temporal conforme a necesidades agrícolas estacionales y en las áreas fronterizas, y estableciendo cuotas anuales para las migraciones intrarregionales (BulmerThomas 1992: 32).

\subsection{Asimetrías regionales y vínculos externos}

Más allá de la aparente homogeneidad que caracteriza a Centroamérica, existen diferencias significativas entre los seis países que integran el SICA respecto a la estructura económica, el grado de participación en el mercado regional, los vínculos comerciales con terceros y la distribución de costes y beneficios de la liberalización. Las asimetrías existentes en la región ya causaron la crisis del MCCA en los años sesenta y setenta. El actual modelo no ha logrado sortearlas -Honduras y Nicaragua, por ejemplo, siguen acumulando déficit comerciales con sus socios- y son uno de los principales obstáculos que hoy enfrenta el proceso. Estas asimetrías debilitan el compromiso integracionista y alimentan tendencias centrífugas.

La estructura del comercio intrarregional muestra con claridad la situación relativa de cada país en el seno del MCCA. Guatemala y El Salvador cuentan con un amplio sector manufacturero orientado al mercado regional. Dicho mercado absorbió en 1995 el 30\% de las exportaciones de Guatemala y el $42 \%$ de El Salvador. Los intercambios entre estos dos países representan en torno al $30 \%$ de todo el comercio intrarregional. La participación de Honduras y Nicaragua en el MCCA es mucho menor en términos porcentuales -un $6 \%$ y un $18 \%$ respectivamente de sus exportaciones- pero éste sigue siendo importante a causa de la debilidad de sus economías. Incluso dentro del CA-4 encontramos "dos velocidades" en el proceso. En julio de 1996 Guatemala y El Salvador decidieron establecer una Unión Aduanera para 1998, a la que podrán sumarse otros países de la región. Panamá y Costa Rica, por su parte, no han seguido el ritmo liberalizador del CA-4. La economía panameña está dominada por los servicios -incluyendo el centro bancario off-shore- y la competitividad de sus manufacturas es menor, por lo que mantiene un régimen arancelario relativamente restrictivo. Al igual que Costa Rica, Panamá ha permanecido al margen de la integración económica y se ha limitado a adoptar acuerdos preferenciales bilaterales con los miembros del MCCA. No es hasta la XIX Reunión Presidencial (julio de 1997) cuando se decide iniciar las negociaciones para la firma de un tratado multilateral de libre comercio entre el MCCA y Panamá.

En lo que se refiere a Costa Rica, el proceso de ajuste estructural y reforma económica de este país ha sido el más temprano de la región, y las exportaciones "no tradicionales" a terceros mercados y el turismo son para su sector externo mucho más importantes que el comercio intrarregional, que sólo absorbe entre el 13\% y el $14 \%$ de sus exportaciones. Diversos sectores empresariales consideran que la adhesión al TLC de América del Norte o la vinculación al mercado mundial sería más ventajosa que la pertenencia al MCCA. Sus tasas de desempleo y empleo informal también son más bajas, por lo que Costa Rica se opone a la libre circulación de trabajadores y de personas. Costa Rica, por ejemplo, no se ha sumado al Acuerdo migratorio CA-4, que permite atravesar las fronteras sin visado. En

10. El programa SIEPAC ha requerido estudios de factibilidad técnica que han durado varios años y que han contado con apoyo del BID, de la Comunidad Europea y de algunos de sus Estados miembros. Recientemente el BID ha anunciado la concesión de créditos por 185,5 millones de dólares -más otros 70 millones aportados por España a través del fondo "V Centenario"- para iniciar los trabajos de interconexión. 
1995 Costa Rica se incorporó al SICA al ratificar el Protocolo de Tegucigalpa, pero no ha ratificado el Protocolo de Guatemala y ha optado por proponer una candidatura propia para adherirse al Ârea de Libre Comercio de las Américas (ALCA) y mantener negociaciones comerciales independientes con otros países.

En enero de 1991 los gobiernos centroamericanos y el de México suscribieron en Tuxtla Gutiérrez un acuerdo marco para establecer una zona de libre comercio. Este compromiso se renovó en la Reunión Tuxtla II de febrero de 1996. A pesar de que los Presidentes Centroamericanos se han comprometido a conducir las negociaciones comerciales de forma conjunta, en la práctica Costa Rica, Panamá y Nicaragua han conducido negociaciones bilaterales, mientras que el "Triángulo del Norte" (Guatemala, El Salvador y Honduras) han optado por una negociación conjunta. (Pleitez 1995 y Guerra-Borges 1995)

El Acuerdo de Libre Comercio Costa Rica-México se firmó el 5 de abril de 1994 y entró en vigor el 1 de enero de 1995. Este Tratado establece un calendario de desgravación arancelaria a lo largo de diez años que comporta la ruptura parcial del Arancel Uniforme Centroamericano de Importación y del compromiso de establecer una estrategia de negociación comercial común frente a terceros, y somete a Costa Rica a reglas más estrictas que las establecidas en Centroamérica en materia de reglas de origen, salvaguardias, competencia desleal y resolución de disputas. Las mejores condiciones de acceso que los productos mexicanos logran con este acuerdo, unidas a su mayor competitividad-acrecentada por la devaluación derivada de la crisis mexicana de 1994- pueden afectar negativamente a las importaciones de los otros cuatro socios regionales. Cabe esperar similares efectos en el caso del Acuerdo de Libre Comercio Nicaragua-México, firmado el 20 de septiembre de 1997 y aún pendiente de ratificación.

Las negociaciones con México, las que se han abierto con Venezuela y Colombia, el Mercado Común del Caribe (CARICOM), la petición de "paridad" de trato con México en el mercado de Estados Unidos y otras iniciativas comerciales impulsadas por la región son un reflejo de la importancia que para Centroamérica tiene el comercio extrarregional, y son una respuesta a los cambios que se han producido en el sistema multilateral de comercio tras la culminación de la "Ronda" Uruguay del GATT (CEPAL 1997a: 49-55). En este contexto, es evidente que Centroamérica mira hacia el norte en sus negociaciones comerciales y que la inserción en el ALCA -vía adhesión al TLC o a través de la convergencia con otros esquemas subregionales de integración- es ahora el marco de referencia ineludible para la integración regional.

En este escenario se plantean nuevos dilemas para la región. La coordinación de las políticas comerciales -o incluso la adopción de una política comercial común frente a terceros- puede otorgar a la región una capacidad de negociación superior a la que se obtendría si cada país negocia por separado, y es funcional a las políticas que promueven la eficiencia y la competitividad al interior del mercado regional. El escenario creado por el TLC y el área de Libre Comercio de las Américas (ALCA), sin embargo, parece estar alentar las tendencias centrífugas y la búsqueda de opciones individuales, desviar a la región de la estrategia del "regionalismo abierto" y, a la postre, fragmentar el MCCA. Aunque formalmente se trata de iniciativas convergentes de cara al objetivo del ALCA, la firma de Acuerdos bilaterales con México parece mostrar que esto ya está ocurriendo, y como ya indicamos, hace cada vez más lejano el objetivo de la Unión Aduanera.

\subsection{El Protocolo de Guatemala y el "Subsistema de la Integración Económica"}

Las diferentes expectativas e intereses respecto al proceso de integración se han reflejado en el contenido y el alcance del Protocolo de Guatemala. Este Protocolo fue suscrito en la XIV "Cumbre" de Presidentes (27-29 de octubre de 1993) y entró en vigor el 17 de agosto de 1995. El Protocolo modifica el Tratado General de la Integración Económica Centroamericana de 1960, establece el "Subsistema de la Integración Económica" en el seno del SICA y define un modelo de integración "de geometría variable" que permite la coexistencia de diferentes situaciones y ritmos, y deja a cada Estado la potestad de fijar sus propios compromisos.

El objetivo del "Subsistema de la Integración Económica", no menos ambicioso que los del SICA, es «(...)alcanzar de manera voluntaria, gradual, complementaria y progresiva la Unión Económica Centroamericana», con objeto de lograr «(...) el desarrollo económico y social equitativo y sostenible de los países centroamericanos, que se traduzca en el bienestar de sus pueblos y el crecimiento de todos los países miembros, mediante un proceso que permita la transformación y modernización de sus estructuras productivas, sociales y tecnológicas, eleve la competitividad y logre una reinserción eficiente y dinámica de Centroamérica en la economía internacional». Según el Protocolo de Guatemala, la integración regional es un "proceso gradual" que comprende distintas etapas y componentes, que van desde la cooperación intergubernamental hasta la integración en sentido estricto:

- El perfeccionamiento de la zona de libre comercio, eliminando barreras arancelarias y no arancelarias.

- La coordinación de las relaciones comerciales externas.

- El perfeccionamiento del Arancel Centroamericano de Importación.

- El establecimiento de la "Unión Aduanera Centroamericana".

- La libre movilidad de los factores productivos (mano de obra y capitales).

- La integración monetaria y financiera, basada en la armonización de las políticas macroeconómicas y fiscales.

- El perfeccionamiento y adopción de políticas sectoriales en los siguientes ámbitos: turismo, agricultura, industria, competencia, derechos del consumidor, infraestructura de transporte y telecomunicaciones, ciencia y tecnología, educación y medio ambiente. 
- La armonización de la legislación en materia de banca, finanzas, seguros, propiedad industrial e intelectual.

El Protocolo no establece calendario alguno para las distintas etapas y políticas del proceso de integración y, como veremos, las decisiones, en principio obligatorias, sólo afectan a aquellos que expresen su conformidad con las mismas. De esta forma nadie puede imponer avances no deseados, ni impedirlos. El Protocolo da así cobertura jurídica a los progresos realizados por el CA-4, y evita que Costa Rica y Panamá queden al margen.

Esta flexibilidad, empero, se ha logrado a costa de elaborar un instrumento muy débil para profundizar el proceso de integración y alcanzar los ambiciosos objetivos planteados. Algunos de estos objetivos pueden ser imposibles de lograr si un Estado miembro suscribe acuerdos comerciales unilaterales con terceros países, algo que el Protocolo permite expresamente siempre que informen previamente al Comité Ejecutivo de Integración Económica y acuerden un mecanismo de coordinación e información sobre los avances de las negociaciones.

Las debilidades de este instrumento también se encuentran en el plano institucional y en relación al proceso de toma de decisiones. El Consejo de Ministros de Integración Económica tiene la potestad de adoptar diversos actos administrativos -Resoluciones, Reglamentos, Acuerdos y Recomendaciones- con distinto grado de obligatoriedad para los Estados miembros. En principio, se establece la superioridad del derecho derivado de la integración sobre el derecho interno, aunque los órganos de los que éste emana sean de naturaleza intergubernamental. El Protocolo, sin embargo, establece que las decisiones se adoptarán por consenso. La falta de consenso no impedirá la adopción de decisiones por parte de algunos países, aunque sólo serán vinculantes para ellos. El Protocolo de Guatemala, por otra parte, crea nuevos órganos e instancias administrativas con competencias que no están delimitadas con precisión, y que en ocasiones se superponen a las que integran el SICA, con la consiguiente confusión y riesgo de duplicidad y solapamiento. Y como hemos visto la hipertrofia institucional que caracteriza al sistema no significa necesariamente que éste tenga mayor eficacia.

Hay que señalar, por último, que el Protocolo de Guatemala no incluye políticas específicas de cohesión para superar las asimetrías y desequilibrios territoriales y sociales que existen dentro del MCCA, y que el actual proceso de liberalización puede contribuir a profundizar. Esta ausencia es particularmente preocupante si recordamos que dichas asimetrías han sido uno de los elementos que condujeron a la crisis del MCCA en el pasado.

\section{4. ¿Hacia una nueva estrategia de integración? Límites de la liberalización y "regionalismo abierto"}

Ir más allá de la limitada liberalización lograda hasta ahora -en otros términos, superar la "etapa fácil" del proceso de integración- y hacer de ésta un verdadero instrumento de desarrollo exige un compromiso político más profundo de los Estados miembros. Las exigencias políticas e institucionales de un esquema de integración avanzado, como puede ser la Unión Aduanera Centroamericana, son mucho más elevadas que las que plantea un área de librecambio y suponen aceptar la pérdida de soberanía nacional en distintos ámbitos. Supone, por ejemplo, crear un nuevo marco normativo e institucional, con capacidad de adoptar normas y hacer efectivo su cumplimiento, sorteando intereses nacionales de corto plazo. Supone definir una política comercial común ante terceros -algo que el Protocolo de Guatemala, como veremos, no propicia al autorizar negociaciones comerciales unilaterales-, coordinar estrechamente la política macroeconómica y cambiaria, adoptar políticas comunes o al menos convergentes en materia de competencia, incentivos a la producción y fiscalidad y ejecutar políticas de apoyo para atenuar los desequilibrios regionales, facilitar la reconversión de los sectores productivos afectados por la liberalización, y promover un estilo de integración que fomente la cohesión interna, en vez de profundizar las asimetrías y desequilibrios ya existentes. Todo ello define una nueva estrategia integracionista -la definida por CEPAL como "regionalismo abierto" - y superar limitados horizontes liberalizadores y condicionantes de corto plazo derivados de las políticas de ajuste estructural del "consenso de Washington".

El "regionalismo abierto" intenta conciliar las políticas de apertura con el mantenimiento de preferencias regionales, con el objeto de que la integración económica esté al servicio de la mejora de la competitividad y, a través de esta, sea un instrumento efectivo de desarrollo económico y social. Lo que diferencia al regionalismo abierto de la mera liberalización comercial es el componente preferencial de los acuerdos de integración, la coordinación de políticas, un marco institucional y normas claras y efectivas, las políticas de apoyo -creación de infraestructura, inversión en capital humano, apoyo a reconversión productiva y a la incorporación de tecnología- que elevan la productividad y la competitividad, y que mejoran -o por lo menos no perjudican- la cohesión social e interterritorial (CEPAL 1994a: 12-15).

A corto y medio plazo, una Unión Aduanera abierta a la economía mundial conforme a las reglas del GATT, pero con elementos preferenciales para la producción regional, con un sólido entramado de políticas de apoyo y con un sistema institucional, decisorio y de resolución de controversias más efectivo, puede ser un instrumento eficaz para fortalecer el proceso de articulación intersectorial de las economías centroamericanas, promover la creación de ventajas dinámicas, lograr mejoras en la competitividad, fomentar el comercio intrarregional y las exportaciones a terceros mercados y de esta forma ser un verdadero instrumento de desarrollo que promueva el crecimiento económico y el empleo, y sustente las políticas sociales que la región precisa para reducir la pobreza y la desigualdad.

\section{REFLEXIONES FINALES}

La reactivación del proceso de integración regional es uno de los acontecimientos más sobresalientes de la 
evolución reciente de América Central. Partiendo de la experiencia histórica de la Federación Centroamericana y el MCCA, la región ha intentado adaptar el proceso a las exigencias del nuevo escenario internacional y, como en el pasado, hacer de la integración un instrumento para promover el desarrollo económico y social y mejorar la inserción internacional del istmo. El nuevo proceso de integración regional, por esta razón, aparece directamente vinculado al proceso de democratización del istmo y tiene una clara dimensión política. La reactivación del proceso de integración también es una respuesta al nuevo escenario internacional de la posguerra fría, en un contexto de reforzamiento de los bloques comerciales y, al mismo tiempo, de apertura multilateral. Por esta razón, la nueva estrategia integracionista pretende fortalecer las capacidades negociadoras de la región, alentar la modernización de las estructuras productivas y la competitividad internacional, y promover una inserción eficiente y dinámica de la región en la economía mundial.

El proceso de integración regional centroamericana ha logrado avances notables en el plano político e institucional, que merecen el reconocimiento de la comunidad internacional por su alcance y por la relativa rapidez, en relación con otros esquemas de integración, con la que se han llevado a cabo. Pero no menos cierto es que en la actualidad el proceso requiere un renovado impulso político y una revisión de su marco jurídico e institucional y de los obstáculos y dificultades que han ido surgiendo en esta corta pero intensa andadura.

\subsection{La Unión Centroamericana: una oportunidad para la reforma institucional y normativa}

Los ambiciosos objetivos que se ha planteado la nueva integración centroamericana, como hemos señalado, contrastan con la debilidad y la confusión que han caracterizado al marco institucional y con las limitaciones de los instrumentos jurídicos y normativos que conforman el SICA. El carácter intergubernamental del Sistema de la Integración Centroamericana y de los diferentes subsistemas, las particularidades del proceso de toma de decisiones y la ausencia de un derecho "comunitario", con rango superior al derecho nacional, son los principales factores limitativos. La confusión existente en cuanto al marco jurídico e institucional se ve agravado por el hecho de que sólo uno de los Tratados de la integración -el Protocolo de Tegucigalpa, que establece el SICA - ha sido ratificado por los seis Estados, existiendo de hecho una "integración a la carta" en la que cada país ha definido cuáles son sus modalidades de participación. El frecuente incumplimiento de los acuerdos de las Reuniones Presidenciales pone de manifiesto la debilidad del marco institucional y normativo frente a los intereses nacionales particulares. La voluntad integracionista, como hemos visto, cede a menudo ante otro tipo de compromisos o, a pesar de la flexibilidad del modelo, ante las exigencias de Acuerdos con terceros. El carácter intergubernamental del proceso puede conducir a que éste no sea capaz de superar la fase inicial de cooperación y que no exista en realidad integración.
Debido a su carácter intergubernamental, el proceso depende casi exclusivamente del impulso de las Reuniones Presidenciales. Sin olvidar que éstas deben asumir el papel director, no existen contrapesos institucionales que contrarresten los riesgos presidencialistas y el "déficit democrático" que caracteriza al proceso. Esta situación es habitual en los comienzos de los procesos de integración política, tal y como sugiere la experiencia histórica. Lo que es difícil es que el proceso pueda avanzar sin un aumento gradual de las competencias que corresponden a los órganos de la integración, incluyendo el Parlacen. Sin éste último, el proceso podrá ganar en eficacia, pero seguirá carente de legitimidad democrática.

La profunda reforma institucional acordada en julio de 1997 y la constitución de la Unión Centroamericana representa una oportunidad histórica para relanzar el proceso y superar sus limitaciones institucionales y normativas. Como han reconocido los propios Presidentes, es el momento de elaborar un nuevo "Tratado Marco" que integre las distintas dimensiones del proceso y establezca un marco institucional único. Ahora bien, si el Tratado de la Unión Centroamericana se limita a dar cobertura jurídica al proceso de racionalización de las instituciones regionales, la oportunidad se habrá perdido. Dicho Tratado debería modificar la naturaleza misma del proceso, atribuyendo a los órganos comunes los poderes necesarios para profundizar el proceso y definir un ordenamiento jurídico que, en aquellos ámbitos que se consideren imprescindibles para lograr los objetivos de la integración, tenga una clara primacía sobre el derecho nacional. En otras palabras, introducir las dosis necesarias de supranacionalidad y superar el limitado marco intergubernamental en el que ahora se asienta el proyecto de "Comunidad Económico-Política" al que aspiran los países del istmo. En este ámbito es particularmente importante revisar las funciones y poderes del Parlacen, otorgando a esta Cámara una participación regular en el proceso decisorio, y asegurar la participación de todos los países de la región en esta Cámara.

Más allá de las iniciativas gubernamentales, el proceso de integración ha sido acompañado por un proceso inédito de regionalización de la sociedad civil y de los movimientos sociales, que puede reforzar el proceso de integración y ser de los principales activos para su democratización y consolidación si se establecen los canales adecuados para que éste se exprese y participe en el mismo. Un buen punto de partida será, superando el secretismo con el que se está conduciendo el proyecto de Unión Centroamericana. impulsar un debate público abierto respecto a su naturaleza, alcance y contenidos.

\subsection{De la liberalización comercial al "Regionalismo abier- to": una nueva estrategia de integración económica}

Las limitaciones del actual proceso de integración son también visibles en el ámbito económico. Como hemos visto, se ha optado por un modelo flexible o "de varias velocidades" que reconoce las asimetrías regionales y ha permitido importantes avances en materia de liberalización comercial y, como consecuencia de ello, los intercambios 
intrarregionales han recuperado niveles similares a los registrados antes de la crisis.

Sin embargo, el incumplimiento de los compromisos, las fuertes tendencias centrífugas al que está sometido el proceso, y las dificultades que existen para profundizarlo, revelan que es necesario dejar atrás el enfoque liberalizador actual, subordinado a la lógica de los programas de ajuste estructural y a los imperativos de la apertura externa, y adoptar un esquema de integración más avanzado según el modelo de "regionalismo abierto". Ello exigiría abordar un amplio programa de acción -a manera de un "Libro Blanco" como el propuesto en 1985 por Jacques Delors, que condujo a la creación del Mercado Único Europeoque abarcara la eliminación de las barreras no arancelarias, la liberalización de los servicios, la convergencia de las políticas macroeconómicas, la adopción de una verdadera política comercial común frente a terceros, el impulso de políticas regionales de infraestructura o desarrollo tecnológico para mejorar la productividad, y programas que faciliten la reconversión de los sectores afectados por la apertura y favorezcan la cohesión interterritorial.

Este enfoque contribuirá a que la integración pueda ser un verdadero instrumento de desarrollo económico y social, contribuya a una mejora real de la competitividad internacional del istmo, y promueva un patrón de desarrollo económico y social equilibrado. Las exigencias del regionalismo abierto como estrategia de integración requieren, en suma, decisiones que van más allá de las que afectan a la creación de una zona de libre cambio y suponen, al igual que en el ámbito de la integración política, poner en común parcelas de soberanía nacional. Este es, en suma, el desafío al que deberá responder la Unión Centroamericana.

\section{REFERENCIAS BIBLIOGRÁFICAS}

ABRAHAM, Gloria (1989), "Integración y democracia en América Central: el papel del Parlamento Centroamericano", en Integración Latinoamericana $\mathrm{n}^{\circ} 146-147$, junio-julio, pp. 68-72.

ALONSO, Eduardo y Ronney Zamora (1996), "Centroamérica: análisis de la situación actual y alternativas de la política arancelaria”, en Integración E Comercio $\mathrm{n}^{\circ} 0$, enero-abril, pp. 136-147.

ARIAS, Salvador y Juan Jované (1992), "La transformación e industrialización de la agricultura del Istmo Centroamericano como eje de una nueva estrategia de desarrollo", en Eduardo Stein y Arias Peñate, Salvador (Coords.), Democracia sin pobreza. Alternativa de desarrollo para el istmo centroamericano. San José: DEI/SELA-CADESCA, pp. 83-145.

Bulmer-THOMAS, Víctor (1991), "La integración económica centroamericana, una visión desde Europa”, en Polémica, $\mathrm{n}^{\circ} 13$, San José: enero-abril, pp. 2 a 8.

BULMER-THOMAS, Víctor (1992), "Regional Integration in Central America: some remarks", en Vv.AA, Prospects for the Processes of Sub-regional integration in Central and South America. Madrid: IRELA/BID, pp. 45-53.
Bulmer-Thomas, Victor (1997), Competitividad y eficiencia: desafios de la nueva integración regional en Centroamérica (Intervención en el seminario "Integración Centroamericana”, celebrado en la casa de América, Madrid, 28-29 de enero de 1997 (mimeo).

Caldentey, Pedro (1997a), El desarrollo económico de Centroamérica en el marco de la integración regional (tesis doctoral). Córdoba. Universidad de Córdoba.

Caldentey, Pedro (1997b), La integración económica de Centroamérica en los años noventa: el establecimiento de la unión aduanera. Ponencia presentada al VI Encuentro de Latinoamericanistas Españoles, 29 de septiembre-1 de octubre (mimeo).

Cepal (1991), La integración en Centroamérica. su evolución desde los años setenta y sus perspectivas en los noventa. México: CEPAL, LC/MEX/R. 271/Rev. 1, 13 de mayo.

CEPAL (1994a), El regionalismo abierto en América Latina y el Caribe. La integración económica al servicio de la transformación productiva con equidad. Santiago de Chile: CEPAL, septiembre, LC/G.1801.

CEPAL (1994b), Salud, equidad y capital bumano en Centroamérica. San José: FLACSO.

Cepal (1995), Desenvolvimiento reciente de los procesos de integración en América Latina y el Caribe. Santiago de Chile: CEPAL, LC/R. 1527, 16 de mayo.

Cepal (1996a), Centroamérica y el TLC: efectos inmediatos e implicaciones futuras. Santiago de Chile: Cuadernos de CEPAL, n ${ }^{\circ}$ 78. LC/MEX/L.265/Rev. 1.

CEPAl (1996b), Las exportaciones de países pequeños en el mercado de los Estados Unidos: Efectos del TLCAN y la devaluación mexicana. México: CEPAL, LC/MEX/R. 571/Re. 1,8 de noviembre.

Cepal (1996c), Centroamérica: evolución económica durante 1996 (evaluación preliminar). México: CEPAL, LC/MEX/R. 585, 19 de diciembre.

CEPAl (1997a), Diagnóstico de la institucionalidad regional centroamericana. México: CEPAL, LC/MEX/R.581/ Rev. 1, 25 de febrero.

CePAL (1997b), Centroamérica: Evolución de la integración económica durante 1996. México. CEPAL, LC/MEX/ L.231, 3 de marzo de 1997.

CETRÉ, Moisés (1996), "Las asimetrías y la transferencia de recursos en el comercio exterior centroamericano", en Comercio Exterior vol. 46, ${ }^{\circ} 5$, mayo, pp. 381-386.

Chamorro, Edgar J. y Rubén E. Nájera (1996), “Orígenes, evolución y perspectivas de la integración centroamericana", en Panorama Centroamericano n ${ }^{\circ} 6$, noviembrediciembre, pp. 29-104.

Совв, Joe (1995), The Caribbean Basin Trade Bill: Good Economic Policy and Good Neighbor Policy. Washington: Heritage Foundation, Memorándum Ejecutivo $n^{\circ}$ 430, 12 de octubre.

Corte Centroamericana de Justicia (1995), Memoria Anual de Labores 12 de octubre de 1994-12 de octubre de 1995. Managua: CCJ.

Corte Centroamericana de Justicia (1996), Memoria Anual de Labores 12 de octubre de 1995-12 de octubre de 1996. Managua: CCJ. 
ECHeverRía, Carlos Manuel y Luis Alberto Chocano (1993), The New Directions of Integration in Central America. Washington: CIPE (Edición electrónica, www.cipe.org).

FEDEPRICAP (1994), Impacto fiscal de las politicas regionales comerciales y mecanismos de compensación. S.L.: Convenio FEDEPRICAP/Unión Europea.

FERnÁndEZ, Lorenzo, Javier García-Lago y Gustavo Palomares (Eds.) (1990), El Parlamento Centroamericano y la experiencia europea. Madrid: Fundación Friedrich Ebert/Instituto de Cooperación Iberoamericana.

GALlARDO, Maria Eugenia (1988), La Iniciativa para la Cuenca del Caribe: Su impacto en Centroamérica. San José: FLACSO.

Gorostiaga, Xavier (1996), "Entre Somalia y Taiwán ¿Hay otra alternativa?”, en Envío, febrero de 1996 (Edición electrónica).

GUERRA-BORGES, Alfredo (1993), "Reestructuración del Mercado Común Centroamericano", en Polémica $\mathrm{n}^{\circ}$ 20-21, abril-diciembre, pp. 56-64.

GuERRA-BORGES, Alfredo (1995), "Negociaciones comerciales entre México y Centroamérica: criterios de negociación y una propuesta industrial", en Álvaro de la Ossa (Comp.), Escenarios de Centroamérica ante los cambios en el entorno económico mundial. San José: FLACSO/Fundación Ebert, pp. 167-197.

Guerra-Borges, Alfredo (s.f.), El Sistema Regional de Pagos en Centroamérica 1961-1992, y la cooperación financiera de la Comunidad Europea. México: CRIES (mimeo).

IICA (1992), Efectos del Tratado de Libre Comercio de América del Norte sobre el acceso de las exportaciones agropecuarias de Centroamérica al mercado de Estados Unidos. San Isidro (Costa Rica): Instituto Interamericano de Cooperación para la Agricultura.

IRELA (1990), El Parlamento Centroamericano: Alternativas de constitución y elecciones. Madrid: IRELA.

IRELA (1994), ¿Una triple renovación en América Central? Elecciones, integración y desarrollo económico. Madrid: IRELA, dossier $\mathrm{n}^{\circ}$ 48, marzo.

JUAN, Rafael de (1996), "El sistema regional de pagos centroamericano: razones de su fracaso y reconversión", en Afers Internacionals $\mathrm{n}^{\circ} 31$.

LiZANO, Eduardo (1994), Desarrollo económico e integración regional en Centroamérica. Washington: BID.

MORALES, Abelardo y Martha Isabel Cranshaw (1997), Regionalismo emergente: redes de la sociedad civil $e$ integración centroamericana. San José: FLACSO/IBIS, abril.
OssA, Álvaro de la (1993). "La nueva integración centroamericana: ¿Otro instrumento del neoliberalismo?”, en Polémica $\mathrm{n}^{\circ}$ 20-21, abril-diciembre, pp. 24-39.

Ossa, Álvaro de la (Comp.) (1994), El Sistema de la Integración Centroamericana: crítica de la visión oficial. San José: Fundación F. Ebert/FLACSO.

Ossa, Álvaro de la (Comp.) (1995), Escenarios de Centroamérica ante los cambios en el entorno económico mundial. San José: FLACSO/Fundación F. Ebert.

Ossa, Álvaro de la (Comp.) (1996), La integración social: nuevas rutas hacia la discordia. San José: FLACSO/ Fundación F. Ebert.

Parlamento Centroamericano (1996), Iniciativas presentadas y aprobadas 1991-1996. Guatemala: Parlamento Centroamericano, Dirección de Comunicación, junio.

PleiteZ, William (1995), "México y el triángulo norte: Estado actual de las negociaciones del Tratado de Libre Comercio", en Álvaro de la Ossa (Comp.), Escenarios de Centroamérica ante los cambios en el entorno económico mundial. San José: FLACSO/ Fundación F. Ebert, pp. 155-166.

QuiNTEROS, Laura (1992), "La nueva etapa de la integración”, en Integración Latinoamericana $\mathrm{n}^{\circ} 179$, junio, pp. 22-27.

RODAS, Haroldo (1994), "Condicionantes externos y perspectivas de la integración económica centroamericana", en Pensamiento Iberoamericano $\mathrm{n}^{\circ} 26$, juliodiciembre de 1994, pp. 181-202.

SANAHUJA, José Antonio (1996), La ayuda norteamericana en Centroamérica, 1980-1992. (Tesis doctoral), Madrid: Universidad Complutense (inédita).

Sanahuja, José Antonio y José Ángel Sotillo (1997), El Parlamento Europeo y la integración centroamericana. Estrasburgo: Parlamento Europeo, Serie Política, W29 (ES).

TuCKER, Stuart R. (1989), "Desentrabamiento del comercio: evaluación de la Iniciativa para la Cuenca del Caribe”, en William Ascher y Ann Hubbard (eds.) Recuperación y desarrollo de Centroamérica. Ensayos del grupo especial de estudios de la Comisión Internacional para la Recuperación y el Desarrollo de Centroamérica (Comisión Sanford), Durham/San José: Duke University Press 1989, pp. 361-398.

Williamson, John (1990), Latin American adjustment. How much has happened? Washington: Institute for International Economics.

Zapata, Ricardo (1994), "Opciones de Centroamérica en sus relaciones comerciales con México: oportunidades y retos", en Integración Latinoamericana $\mathrm{n}^{\circ}$ 198-199, marzo-abril, pp. 3-14. 


\section{EL SICA SEGÚN EL PROTOCOLO DE TEGUCIGALPA}

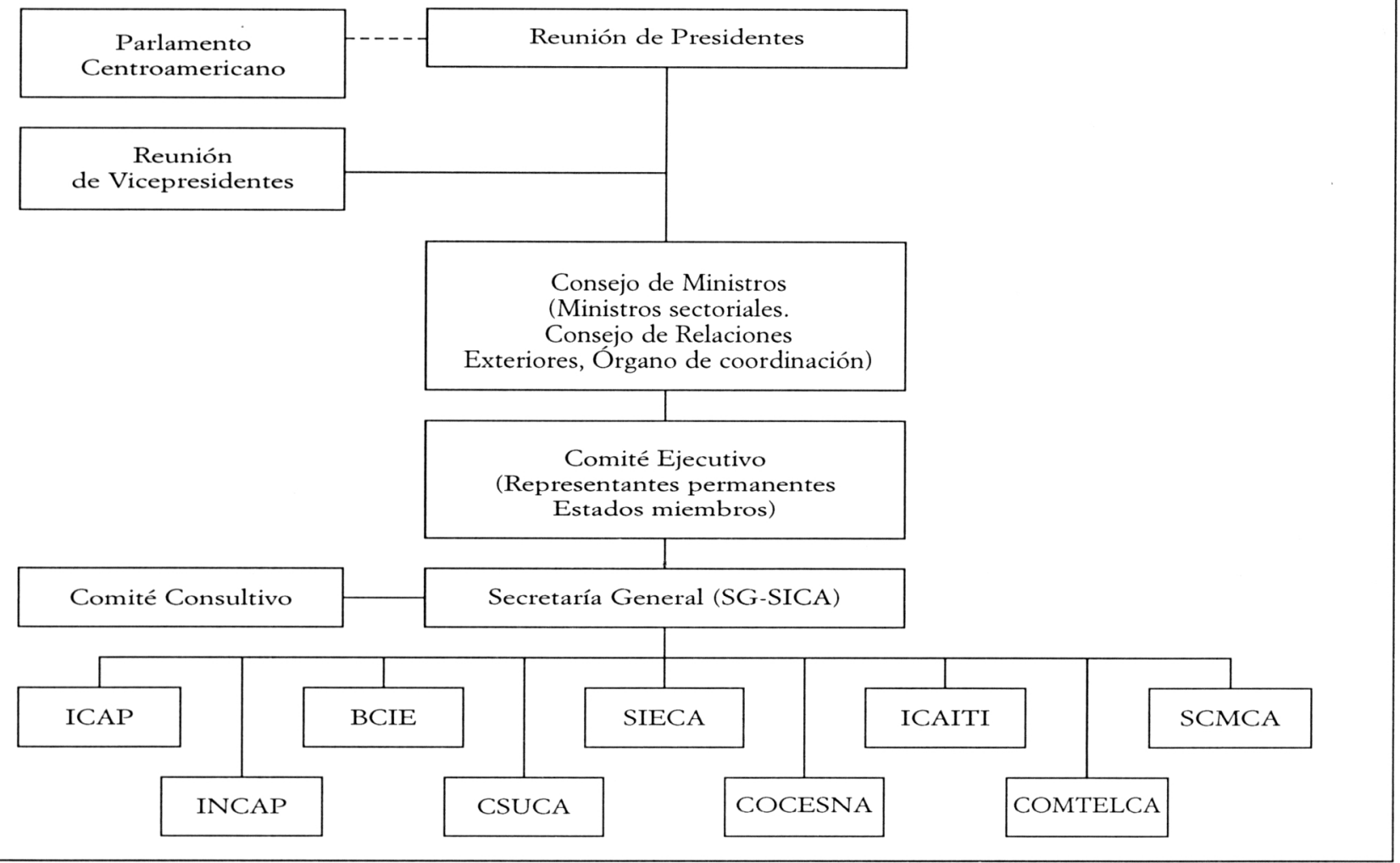

CUADRO 2

\section{EL MARCO JURÍDICO DE LA INTEGRACIÓN CENTROAMERICANA}

\begin{tabular}{|c|c|c|c|c|c|c|c|}
\hline & Entrada en vigor & Costa Rica & El Salvador & Guatemala & Honduras & Nicaragua & Panamá \\
\hline $\begin{array}{l}\text { Protocolo de Tegucigalpa. } \\
\text { 13-XII-91 } \\
\text { (Integración política) }\end{array}$ & 23-XII-92 & 26-VI-95 & 5-VI-92 & 13-VIII-93 & 8-VI-92 & 14-VII-92 & 26-III-96 \\
\hline $\begin{array}{l}\text { Estatutos de la Corte } \\
\text { Centroamericana de } \\
\text { Justicia. 10-XII-92 }\end{array}$ & 2-II-94 & $\begin{array}{l}\text { No se ha } \\
\text { depositado }\end{array}$ & $24-X I-93$ & $\begin{array}{l}\text { No se ha } \\
\text { depositado }\end{array}$ & 24-I-94 & 19-I-94 & $\begin{array}{r}\text { No se ha } \\
\text { depositado }\end{array}$ \\
\hline $\begin{array}{l}\text { Protocolo de Guatemala. } \\
29-X I I-93 \\
\text { (Integración Económica) }\end{array}$ & 17-VIII-95 & $\begin{array}{l}\text { No se ha } \\
\text { depositado }\end{array}$ & 8-VIII-95 & 6-V-96 & 8-VIII-95 & 8-VIII-95 & $\begin{array}{r}\text { No se ha } \\
\text { depositado }\end{array}$ \\
\hline $\begin{array}{l}\text { Tercer Protocolo al } \\
\text { Tratado Constitutivo del } \\
\text { Parlacen 20-VIII-94 }\end{array}$ & $\begin{array}{l}\text { No ha } \\
\text { entrado en } \\
\text { vigor }\end{array}$ & $\begin{array}{l}\text { No se ha } \\
\text { depositado }\end{array}$ & 24-VII-95 & $\begin{array}{l}\text { No se ha } \\
\text { depositado }\end{array}$ & $\begin{array}{l}\text { No se ha } \\
\text { depositado }\end{array}$ & 20-VI-95 & $\begin{array}{r}\text { No se ha } \\
\text { depositado }\end{array}$ \\
\hline $\begin{array}{l}\text { Tratado de Integración } \\
\text { Social. 30-III-95 }\end{array}$ & $15-\mathrm{V}-96$ & 23-XII-96 & 31-VIII-95 & 6-V-96 & $\begin{array}{l}\text { No se ha } \\
\text { depositado }\end{array}$ & 1-VIII-96 & 26-III-96 \\
\hline $\begin{array}{l}\text { Tratado de Integración } \\
\text { Democrática. 15-XII-95 }\end{array}$ & $\begin{array}{c}\text { No ha } \\
\text { entrado en vigor }\end{array}$ & $\begin{array}{l}\text { No se ha } \\
\text { depositado }\end{array}$ & 24-XI-93 & $\begin{array}{l}\text { No se ha } \\
\text { depositado }\end{array}$ & $\begin{array}{l}\text { No se ha } \\
\text { depositado }\end{array}$ & 19-VIII-96 & $\begin{array}{l}\text { No se ha } \\
\text { depositado }\end{array}$ \\
\hline
\end{tabular}




\section{RESUMEN}

Entre 1990 y 1997 América Central ha definido un nuevo marco institucional y normativo y una nueva estrategia económica para el proceso de integración regional. En el plano institucional, la flexibilidad y el gradualismo han sido los dos principios rectores. En el plano económico se ha intentado hacer compatible la profundización del mercado regional con la apertura al exterior. Siete años después, sin embargo, esta estrategia ha mostrado sus límites políticos, económicos y sociales. La continuidad del proceso y el éxito de la Unión Centroamericana propuesta en 1997 exige una reorientación del modelo y compromisos integracionistas más profundos. El artículo describe el proceso de integración en el periodo citado, evalúa sus resultados en el plano político y económico, y trata de identificar los desafíos y opciones futuras de la Unión Centroamericana, prestando atención a la reforma institucional propuesta en julio de 1997.

Palabras clave: América Central, integración, liberalización comercial, regionalismo, Unión Centroamericana.

\section{ABSTRACT}

Since 1990 to 1997 Central America has defined a new set of norms and institutional frameworks, as well as a new economic strategy for the regional integration process. In the institutional field, flexibility and gradualism have been the leading principles. Economics has been directed by the search of compatibility between the deepening the regional market and the opening up to world markets. However, seven years later the strategy has proved to be limited by economical, political and social constraints. The continuity of the process and the success of the Central American Union launched in 1997, demands a new direction of the model and more profound integration commitments. The paper describes the integration process in the aforementioned period, evaluates its economic and political outcomes, and intends to identify the future challenges and options of the Central American Union, taking into account the institutional reform proposed in July 1997.

Key words: Central America, integration, commercial liberalization, regionalism, Centroamerican Union

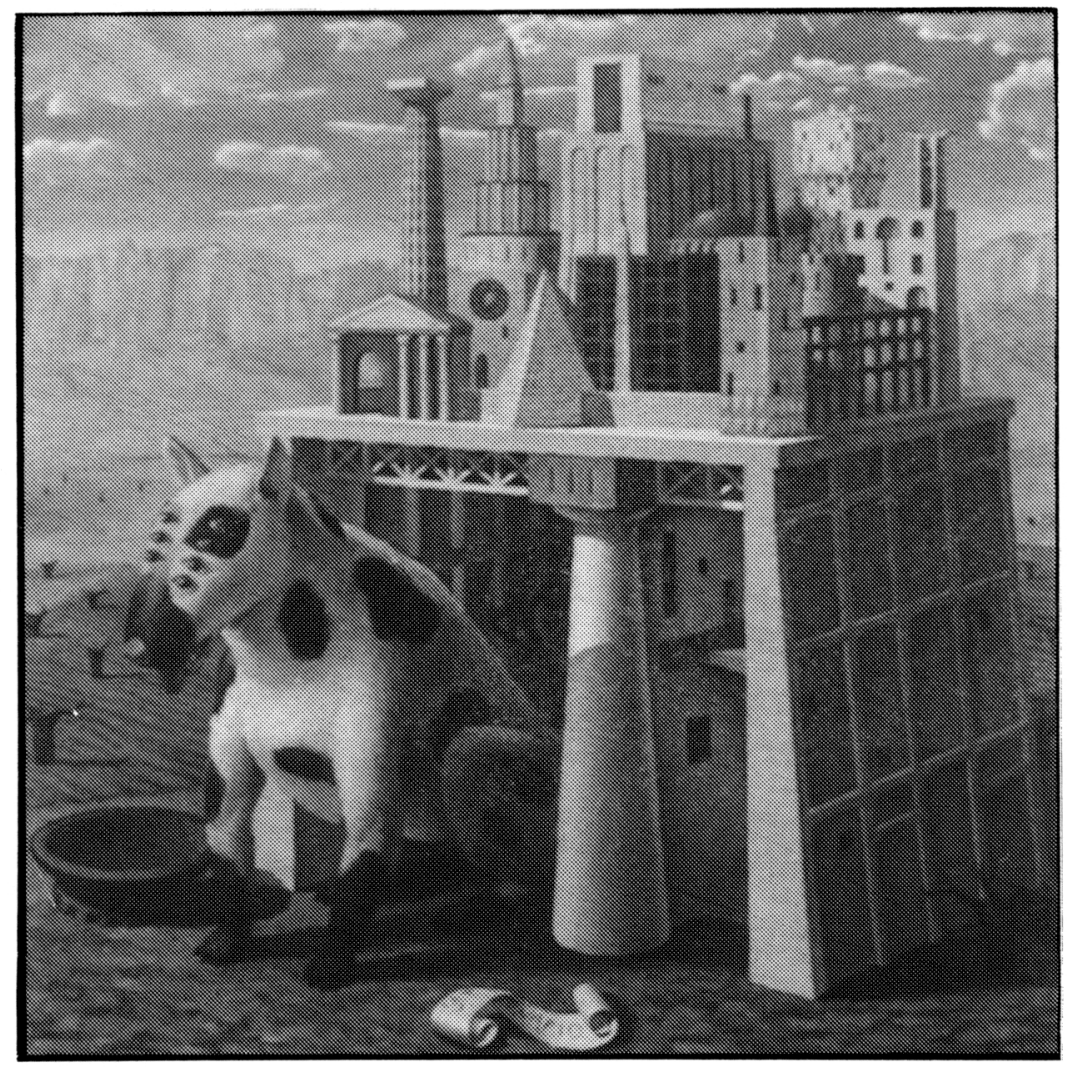

